\title{
Investigation on the Metabolic Regulation of pgi gene knockout Escherichia coli by Enzyme Activities and Intracellular Metabolite Concentrations
}

\author{
Nor 'Aini, A. R. ${ }^{{ }^{\star}}$, Shirai, Y. $^{3}$, Hassan, M.A. ${ }^{1}$ and Shimizu, K. ${ }^{2}$ \\ ${ }^{1}$ Department of Bioprocess Technology, Universiti Putra Malaysia 43400, Serdang, Selangor, Malaysia. \\ ${ }^{2}$ Department of Bioscience and Bioinformatics, Kyushu Institute of Technology, lizuka, \\ Fukuoka, 820-8502, Japan. \\ ${ }^{3}$ Department of Biological Function and Engineering, Kyushu Institute of Technology, \\ 2-4 Hibikino, Wakamatsu-ku, Kitakyushu. \\ Email: nor_aini@biotech.upm.edu.my
}

\begin{abstract}
An integrated analysis of the cell growth characteristics, enzyme activities, intracellular metabolite concentrations was made to investigate the metabolic regulation of pgi gene knockout Escherichia coli based on batch culture and continuous culture which was performed at the dilution rate of $0.2 \mathrm{~h}^{-1}$. The enzymatic study identified that pathways of pentose phosphate, ED pathway and glyoxylate shunt were all active in pgi mutant. The glycolysis enzymes i.e glyceraldehyde-3-phosphate dehydrogenase, fructose diphosphatase, pyruvate kinase, triose phosphate isomerase were down regulated implying that the inactivation of pgi gene reduced the carbon flux through glycolytic pathway. Meanwhile, the pentose phosphate pathway was active as a major route for intermediary carbohydrate metabolism instead of glycolysis. The pentose phosphate pathway generates most of the major reducing co-factor NADPH as shown by the increased of $\mathrm{NADPH} / \mathrm{NADP}^{+}$ratio in the mutant when compared with the parent strain. The fermentative enzymes such as acetate kinase and lactate dehydrogenase were down regulated in the mutant. Knockout of pgi gene results in the significant increase in the intracellular concentration of glucose-6-phosphate and decrease in the concentration of oxaloacetate. The slow growth rate of the mutant was assumed to be affected by the accumulation of glucose-6-phosphate and imbalance of NADPH reoxidation.
\end{abstract}

Keywords: pgi mutant; enzyme activity; intracellular metabolite, Escherichia coli

\section{INTRODUCTION}

It is quite important to understand the metabolic regulation from various levels such as gene expression, protein expression, and metabolic flux distribution in response to genetic modification. Intracellular metabolite concentrations and enzymes activities are important parameters in elucidating the in vivo regulatory mechanisms and evaluating the effect of genetic modifications on the cell metabolism.

Phosphoglucose isomerase (Pgi: D-glucose 6phosphate ketoisomerase; EC 5.3.1.9) is the first enzyme specific for glycolytic pathway, catalyzes the isomerization reaction between glucose-6-phosphate (G6P) and fructose-6-phosphate (F6P). Phosphoglucose isomerase is located at the junction of the different pathways for glucose catabolism and thus, its inactivation forces the glucose catabolism via the pentose phosphate (PP) pathway (Gamo, 1993). As a consequence, metabolic redirection in a pgi mutant overproduces $\mathrm{NADPH}$, and thus may inhibit the cell growth due to NADPH imbalance. In E.coli, the PP pathway is the major route for the intermediary carbohydrate metabolism, next to the glycolysis. The PP pathway plays various roles including the breakdown of carbon sources, the generation of reducing power (NADPH) and provides essential

\section{${ }^{*}$ Corresponding author}

metabolites for biosynthesis and the formation of the components of the cell's lipopolysaccharide layer of the cells (Sprenger, 1995).

In the present study, the effect of pgi gene knockout on the metabolism of E.coli was investigated by measuring some enzyme activities in the central metabolic pathways and intracellular metabolite concentrations for both batch and continuous cultures at the dilution rate of $0.2 \mathrm{~h}^{-1}$.

\section{MATERIALS AND METHODS}

\section{Strains}

The strains used throughout this study are Escherichia coli BW 25113 ( $F \lambda^{-}$rph-14 araBAD AH33 lacl $^{9} \Delta$ lac $Z_{W J 16}$ $r r n B_{\mathrm{T} 14} \Delta r h a B A D_{\mathrm{LD} 78}$ hsdR514) and pgi knockout mutant JWK3985. Mutant strain JW 3985 was constructed at Keio University, Japan using the method of Datsenko and Wanner (2000) by Mori et al. (http://www.ttck.keio.ac.jp/ IAB/english/research/index.htm). The pgi gene knockout was verified by comparing the length of PCR-amplified fragments with the expected length from the genome database (http://ecoli.aist-nara.ac.jp). Disruption of pgi gene was further confirmed by measuring in vitro enzyme activity of phosphoglucose isomerase in the cell extract from the mutant (data not shown). 


\section{Medium and Growth Conditions}

Both E.coli strains were cultivated in a minimal medium containing (in gram per liter) $1.0 \mathrm{~g}$ of $\mathrm{NH}_{4} \mathrm{Cl}, 2.7 \mathrm{~g}$ of $\mathrm{NH}_{4} \mathrm{SO}_{4}, 6.8 \mathrm{~g}$ of $\mathrm{Na}_{2} \mathrm{HPO}_{4}, 3.0 \mathrm{~g}$ of $\mathrm{KH}_{2} \mathrm{PO}_{4}, 0.6 \mathrm{~g}$ of $\mathrm{NaCl}, 0.2 \mathrm{~g}$ of $\mathrm{MgSO}_{4} .7 \mathrm{H}_{2} \mathrm{O}, 1.0 \mathrm{~g}$ thiamine $\mathrm{HCl}$ and $10 \mathrm{ml}$ of trace element solution containing (per liter) $0.55 \mathrm{~g}$ of $\mathrm{CaCl}_{2} .2 \mathrm{H}_{2} \mathrm{O}$, 1.67 of $\mathrm{FeCl}_{3} \cdot 6 \mathrm{H}_{2} \mathrm{O}, 0.10 \mathrm{~g}$ of $\mathrm{MnCl}_{4} .4 \mathrm{H}_{2} \mathrm{O}$, $0.17 \mathrm{~g}$ of $\mathrm{ZnCl}_{2}, \quad 0.04 \mathrm{~g}$ of $\mathrm{CuCl}_{2} .2 \mathrm{H}_{2} \mathrm{O}, 0.06 \mathrm{~g}$ of $\mathrm{CoCl}_{2} .6 \mathrm{H}_{2} \mathrm{O}$ and $0.06 \mathrm{~g}$ of $\mathrm{Na}_{2} \mathrm{MoO}_{4} .4 \mathrm{H}_{2} \mathrm{O}$ (Kabir et al., 2005). Glucose was used as a sole carbon source. In batch culture, $10 \mathrm{~g} / \mathrm{l}$ of initial glucose was used, while in continuous culture, $4 \mathrm{~g} / \mathrm{l}$ of glucose was fed.

Batch cultivation and continuous cultivation were performed in a 1 liter fermenter (MDL B.E. Marubishi) at $37^{\circ} \mathrm{C}$ with a working volume of $500 \mathrm{ml}$ equipped with temperature and $\mathrm{pH}$ sensors. The inoculum was prepared by transferring cells from glycerol stock $(0.2 \mathrm{ml})$ by pipetting using a micropipetter to a $50 \mathrm{ml}$ T-shaped tube containing $10 \mathrm{ml}$ of LB medium. The culture was incubated for 24 hours, and $1 \mathrm{ml}$ of the broth was then transferred into a $500 \mathrm{ml}$ T-shaped flask containing $100 \mathrm{ml}$ of LB medium, and the cultivation was continued until 8 hours after the inoculation, which corresponds to the exponential growth phase. The cells were then harvested by centrifugation of culture broth at $12,000 \mathrm{rpm}$ for $10 \mathrm{~min}$ at $4^{\circ} \mathrm{C}$. For batch culture, the cells were harvested during exponential growth phase (at 7 hours fermentation) and then transferred to the fresh medium. In continuous cultivation, the culture medium was continuously fed to the bioreactor at a dilution rate, $D$ of $0.2 \mathrm{~h}^{-1}$, and the working volume was kept constant by removing the culture broth using a peristaltic pump. The $\mathrm{pH}$ of the culture was maintained at 7.0 by addition of $2 \mathrm{M} \mathrm{NaOH}$ and $2 \mathrm{M} \mathrm{HCl}$. Aerobic condition was attained with agitation speed of 350 rpm and a constant air flow of $1.0 \mathrm{vvm}$.

\section{Measurement of biomass and extracellular metabolite concentrations}

Cell growth was monitored by measuring the optical density (OD) at $600 \mathrm{~nm}$, and the dry cell weight (DCW) was calculated based on previously determined OD to DCW relationship. Dry cell weight was determined from the cell pellets of $100 \mathrm{ml}$ culture aliquots that were centrifuged for $10 \mathrm{~min}$ at $5,000 \mathrm{rpm}$ and $4^{\circ} \mathrm{C}$, washed once with distilled water and then dried at $100^{\circ} \mathrm{C}$ overnight. For the measurement of extracellular metabolite concentrations, the culture samples were centrifuged at $10,000 \mathrm{rpm}$ for $5 \mathrm{~min}$ at $4^{\circ} \mathrm{C}$ and 10,000 $\mathrm{rpm}$ to remove the debris. Glucose concentration was determined using an enzymatic test kit (Wako, Co., Osaka). The concentrations of acetate and lactate were determined by using test kits (Wako, Co.) and confirmed using HPLC (LC-10AC, Shimadzu, Tokyo, Japan) with a column Shim PACK SCR-10ZH (Shimadzu, Tokyo, Japan) with $7 \mathrm{mM}$ sulfuric acid as the mobile phase and flow rate at $0.6 \mathrm{ml} / \mathrm{min}$. Oxygen and carbon dioxide concentrations in the bioreactor off-gas were measured by the off-gas analyzer (LX-lijima Electronics Co., Japan).

\section{Enzyme Assays}

Samples for enzyme assays were taken during the exponential growth phase for batch cultivation, while for continuous cultivation, samples were taken after the culture reached the steady state for at least four culture volume changes. Crude extracts were prepared as follows: $100 \mathrm{ml}$ of the broth was harvested and centrifuged at $5,000 \mathrm{rpm}$ at $4^{\circ} \mathrm{C}$ for $10 \mathrm{~min}$. The cell pellet was then washed and resuspended in disruption buffer, which contained $100 \mathrm{mM}$ Tris $\mathrm{HCl}(\mathrm{pH} 7.6), 4 \mathrm{mM} \mathrm{MgCl}$, $2 \mathrm{mM}$ DTT. Cells were disrupted for $5 \mathrm{~min}$ by sonication in the ultrasonic distrupter (TOMY UD-201, Tokyo, Japan) with $30 \mathrm{~s}$ intervals between each step. The cell debris was separated by centrifugation at $10,000 \mathrm{rpm}$ for $10 \mathrm{~min}$ at $4^{\circ} \mathrm{C}$. The supernatant was kept at $-20^{\circ} \mathrm{C}$ prior to use for enzyme activity measurement. Enzyme activities were measured spectrophotometrically in a thermostatically controlled $\left(30^{\circ} \mathrm{C}\right)$ recording spectrophotometer (U-200A, Hitachi, Co., Japan). All compounds of the reaction mixture were pipetted into a cuvette with a $1 \mathrm{~cm}$ light path, and the reactions were initiated by adding the cell extract to give the final volume of $1 \mathrm{ml}$. The wavelength and the milimolar extinction coefficients for $\mathrm{NAD}^{+}, \mathrm{NADH}, \mathrm{NADP}^{+}$, NADPH were $340 \mathrm{~nm}$ and $6.22 \mathrm{~cm}^{-1} \mathrm{mM}^{-1}$ respectively, and those for acetyl-CoA were $412 \mathrm{~nm}$ and $13.6 \mathrm{~cm}^{-1} \mathrm{mM}^{-1}$, respectively. One unit $(U)$ of the specific enzyme activity was defined as the amount of enzyme required to convert $1 \mu \mathrm{mol}$ of substrate into the specific product per minute per mg of protein. Each measurement was performed at least three times.

Enzyme activities of phosphoenolpyruvate carboxylase, pyruvate kinase and $\mathrm{NADP}^{+}$-specific malic enzyme were determined according to Petersen et al. (2001). Enzyme activities of isocitrate lyase, malate synthase and isocitrate dehydrogense were determined according to Wang et al. (2003). Enzyme activities of phosphoglucose isomerase, hexokinase, glucose-6phosphate dehydrogenase, 6-phosphogluconate dehydrogenase, fructose diphosphatase, phosphofructose kinase, glyceraldehydes-3-phosphate dehydrogenase and triosephosphate isomerase were determined as described by Dominguez et al. (1998). Enzyme activity of lactate dehydrogenase was determined according to Schreyer and Bock (1980). Acetate kinase was assayed by the method described by Riondet et al. (2000) and citrate syntase was measured as described by Kyra et al. (2000). Enzyme activities of Entner-Doudoroff pathway were determined from the combined Edd (EC 4.1.1.12) and Eda (EC 4.1.2.14) reactions (Canonaco et al., 2001). Enzyme activity of transhydrogenases was performed by the method described by Sauer et al. (2003). Protein assay rapid kit (Wako, Co.) was used to determine the protein concentration based on the Bradford Method (1976). 


\section{Determination of intracellular metabolite concentrations}

Ten milliliters of culture broth was quickly taken and immediately injected into $30 \mathrm{ml}$ of pre-cooled quenching solution, $60 \%(\mathrm{v} / \mathrm{v})$ aqueous methanol. The addition of the sample with an initial temperature of $37^{\circ} \mathrm{C}$ into the precooled methanol resulted in a rapid quenching of the metabolism of the cells in the sample. The samples were centrifuged for $10 \mathrm{~min}$ at $5,000 \mathrm{rpm}$ at the temperature of $0^{\circ} \mathrm{C}$. The supernatant was removed and the pellets were kept in $-20^{\circ} \mathrm{C}$ freezer for being solidified and then freeze dried. The dried biomass was kept in $-20^{\circ} \mathrm{C}$ freezer for further analysis. Intracellular metabolites except NADPH and NADH were extracted using $21 \%(\mathrm{v} / \mathrm{v})$ perchloric acid. Then, the cell debris and perchloric acid were removed by centrifugation at $10,000 \mathrm{rpm}$ within $15 \mathrm{~min}$ at $4^{\circ} \mathrm{C}$. Neutralization of the supernatant was achieved by carefully addition of the solution containing $\mathrm{KH}_{2} \mathrm{PO}_{4}$, $\mathrm{Na}_{2} \mathrm{PO}_{4}, \mathrm{KOH}$ and EDTA. The resulting precipitate was removed by centrifugation at $10,000 \mathrm{rpm}$ for $15 \mathrm{~min}$ at $4^{\circ} \mathrm{C}$. For measurement of $\mathrm{NADPH}$ and $\mathrm{NADH}$, alkaline extraction was performed according to Bergmeyer (1984). Enzymatic determination of intracellular metabolites was performed with spectrofluorometer (Jasco FP 6500) at 340 and $460 \mathrm{~nm}$ wavelength pair, and temperature was controlled at $30^{\circ} \mathrm{C}$. The volume of the assay mixture was $100 \mu \mathrm{l}$, and total volume was $2.0 \mathrm{ml}$. Intracellular metabolite concentrations of Glucose-6-phosphate (G6P), Pyruvate (PYR), Fructose 1,6-biphosphate (FDP), Oxaloacetate (OAA), $\alpha$-ketoglutarate (AKG), NAD ${ }^{+}$, $\mathrm{NADP}^{+}, \mathrm{NADPH}$ and NADH were measured according to the published protocols (Bergmeyer 1984, 1985) with some modifications. All the intracellular metabolite concentrations are shown as the average of three measurements with the standard deviations.

\section{RESULTS}

\section{Fermentation characteristics}

Both E.coli BW25113 (parent strain) and E.coli JW 3985 (pgi mutant) were cultivated aerobically on glucose as a sole carbon source in order to elucidate the physiological responses to pgi gene deletion. Complete inactivation of pgi gene in E.coli JW3985 was confirmed by the measurement of phosphoglucose isomerase activity. Batch cultivation results for both strains grown on glucose under aerobic condition are shown in Figure 1. Growth parameters at the exponential growth phase are shown in Table 1. The results indicated that the cell growth of the mutant was slow as compared with its parent strain (Table 1). Glucose was fully consumed after 8 hours fermentation for the parent strain while, the glucose for the mutant was depleted at 17 hours fermentation (Figure 1). The concentration of acetate was very low (almost undetectable) in the mutant (Figure 1b) while in the case of the parent strain, the acetate produced was as much as $1.8 \mathrm{~g} / \mathrm{L}$ (Figure 1a). The concentration of other organic acids such as lactate, succinate, pyruvate and propionate were measured however those organic acids were undetectable for both strains. Although the cell growth was depressed in the mutant, the final concentration was higher than that of the parent strain (Figure 1b). The biomass yield on glucose of pgi mutant was higher as compared with the parent strain (Table 1). This phenomenon might be due the fact that less acetate and $\mathrm{CO}_{2}$ were produced by the mutant strain.
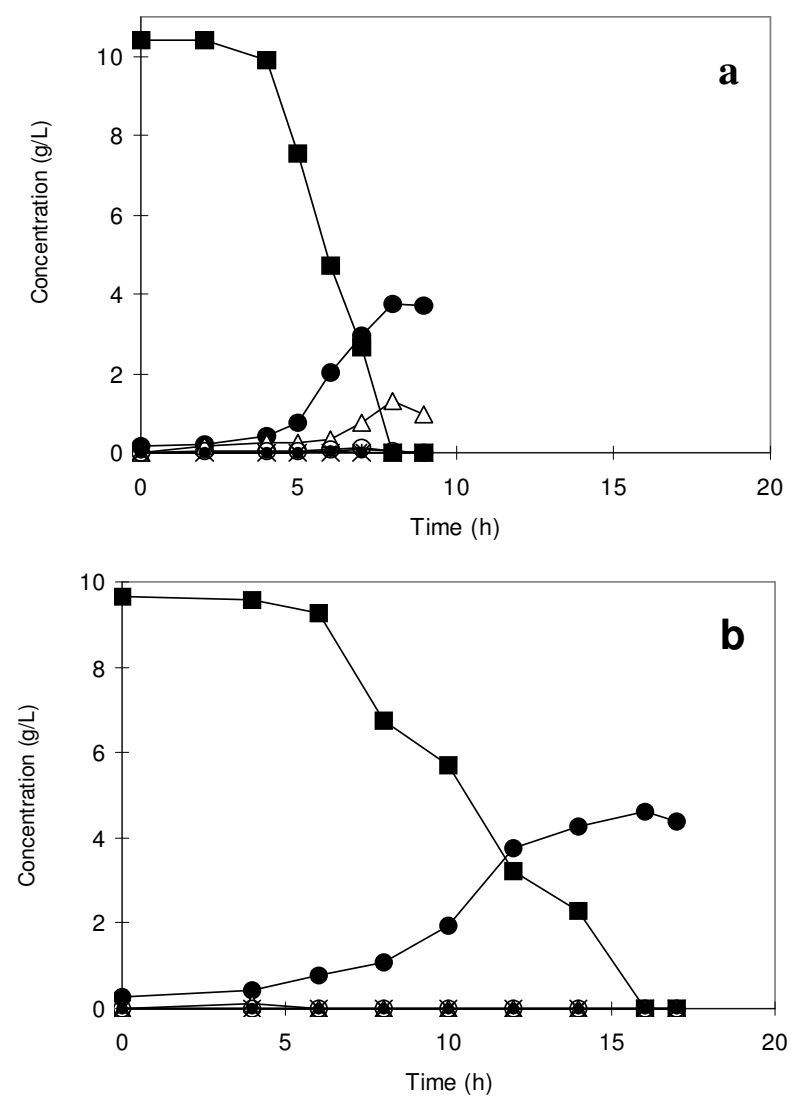

Figure 1: Time course of batch culture of parent Escherichia coli BW25113 (a) and pgi mutant (b) grown on glucose under aerobic condition. $(\bullet)$ Biomass, Glucose $(\boldsymbol{\square})$, Acetate $(\Delta)$, Lactate $(\mathrm{O})$, Succinate $(\diamond)$, Pyruvate $(*)$, Propionate $(\times)$.

Table 1: Specific rates and the cell yield of E.coli strains

\begin{tabular}{lcc}
\hline & BW 25113 & pgi mutant \\
\hline$\mu\left(\mathrm{h}^{-1}\right)$ & 0.41 & 0.23 \\
$\mathrm{Q}_{\mathrm{glc}}\left(\mathrm{mmol}^{-1} \mathrm{~g}^{-1} \mathrm{~h}^{-1}\right)$ & 6.46 & 2.52 \\
$\mathrm{Q}_{\mathrm{CO} 2}\left(\mathrm{mmol}^{-1} \mathrm{~g}^{1} \mathrm{~h}^{-1}\right)$ & 5.21 & 1.76 \\
$\mathrm{Q}_{\text {ace }}\left(\mathrm{mmolg}^{-1} \mathrm{~h}^{-1}\right)$ & 2.03 & 0 \\
$\mathrm{Y}_{\mathrm{x} / \mathrm{s}}\left(\mathrm{g} \cdot \mathrm{g}^{-1}\right)$ & 0.37 & 0.44 \\
\hline
\end{tabular}

$\mu$ : specific growth rate; $\mathrm{Q}$ : specific uptake/production rate; $\mathrm{Yx} / \mathrm{s}$ : biomass yield; glc: glucose;ace: acetate. 


\section{Enzyme activities}

Twenty-four different enzyme activities involved in the central metabolic pathway including the glycolytic, anaplerotic, pentose phosphate, Entner-Doudoroff (ED), and fermentative pathway as well as part of the TCA cycle were measured for both pgi mutant and the parent strain at the exponential growth phase for batch culture and at the steady state for continuous cultivation to elucidate the metabolic phenotype of the mutant. To visualize how each enzyme activity was affected, the ratio of enzyme activity for the pgi mutant over the corresponding value in the parent strain was calculated. The glycolytic enzymes measured consisting of phosphofructose kinase, fructose diphosphatase, triosephosphate isomerase, glyceraldehyde-3-phosphate dehydrogenase, phosphoglucose kinase and pyruvate kinase were found to be down regulated in the pgi mutant for both batch and continuous cultivation as compared to the parent strain (Table 2 and 3 ). This phenomenon is expected since the glycolysis pathway is less active as a consequence of pgi gene deletion. The two enzymes involved in the oxidative pentose phosphate pathway, glucose-6-phosphate dehydrogenase (G6PDH) and 6-phosphogluconate dehydrogenase (6PGDH) that provide NADPH for biosynthesis, were affected in pgi mutant E.coli grown on glucose under aerobic condition in continuous culture (Table 2 and 3). The 6PGDH was increased by 2 folds, while G6PDH increased by 1.4 folds in the pgi mutant compared to the parent strain in continuous culture (Table 3 ). The activities of fermentative pathway enzymes such as acetate kinase and lactate dehydrogenase decreased significantly in pgi mutant (Table 2 and 3). The down regulation of acetate kinase and lactate dehydrogenase agreed with the fermentation results (Fig. 1b), which shows low acetate and lactate production. The overall activity of ED pathway enzyme combining 6phosphogluconate dehydratase (6PGD) and 2-keto-3deoxy-6-phosphogluconate aldolase (2KDPGA) was assayed by measuring 6-PG-dependent formation of pyruvate. Basically, this assay procedure measures the rate-limiting component (6PGD) in the pathway, as 2KDPGA is usually present in excess compared to 6PGD. It can be seen in Table 2 and 3 that the ED pathway was found to be upregulated significantly ( 2 folds in batch and 5 folds in continuous cultivation) in pgi mutant as compared to the parent strain. It was shown that the anaplerotic enzymes such as phosphoenol pyruvate carboxylase, phosphoenol pyruvate kinase and NADPspecific malic enzyme were not much affected by the deletion of pgi gene as compared to the parent strain (Table 3). As for the glyoxylate shunt enzymes, the isocitrate lyase and malate syntase were found to be upregulated by 1.7 and 1.3 fold, respectively in continuous culture (Table 3 ) while for the batch culture shown highly upregulated of isocitrate lyase by 16 folds for the mutant as compared with the parent strain (Table 2).
Table 2: Comparison of the enzyme activities in cell extracts of the wild type and pgi mutant in batch culture under aerobic condition.

\begin{tabular}{|c|c|c|c|}
\hline Enzyme & BW 25113 & pgi mutant & Ratio \\
\hline $\begin{array}{l}\text { 1Phosphoglucose } \\
\text { isomerase }\end{array}$ & $2.52 \pm 0.12$ & $\begin{array}{l}0.0084 \pm \\
0.0005\end{array}$ & 0.003 \\
\hline Glucokinase & $0.41 \pm 0.006$ & $0.51 \pm 0.01$ & 1.24 \\
\hline Phosphofructose kinase & $1.30 \pm 0.04$ & $0.65 \pm 0.013$ & 0.50 \\
\hline Fructose diphosphatase & $0.11 \pm 0.0033$ & $0.087 \pm 0.002$ & 0.79 \\
\hline $\begin{array}{l}\text { Triosephosphate } \\
\text { isomerase }\end{array}$ & $0.12 \pm 0.004$ & $0.11 \pm 0.003$ & 0.92 \\
\hline $\begin{array}{l}\text { Glyceraldehyde 3- } \\
\text { phosphate } \\
\text { dehydrogenase }\end{array}$ & $3.42 \pm 0.161$ & $0.48 \pm 0.051$ & 0.14 \\
\hline Phosphoglucokinase & $7.68 \pm 0.505$ & $7.13 \pm 0.09$ & 0.93 \\
\hline Pyruvate kinase & $0.55 \pm 0.022$ & $0.32 \pm 0.04$ & 0.58 \\
\hline $\begin{array}{l}\text { Glucose-6-phosphate } \\
\text { dehydrogenase }\end{array}$ & $0.43 \pm 0.032$ & $0.55 \pm 0.006$ & 1.28 \\
\hline $\begin{array}{l}\text { 6-Phosphogluconate } \\
\text { dehydrogenase }\end{array}$ & $0.51 \pm 0.002$ & $0.66 \pm 0.004$ & 1.29 \\
\hline $\begin{array}{l}\text { Phosphoenol pyruvate } \\
\text { carboxylase }\end{array}$ & $0.097 \pm 0.04$ & $0.076 \pm 0.002$ & 0.78 \\
\hline $\begin{array}{l}\text { Phosphoenol pyruvate } \\
\text { carboxykinase }\end{array}$ & $0.071 \pm 0.016$ & $0.066 \pm 0.04$ & 0.93 \\
\hline $\begin{array}{l}\text { NADP }^{+} \text {-specific malic } \\
\text { enzim }\end{array}$ & $0.11 \pm 0.01$ & $0.17 \pm 0.002$ & 1.55 \\
\hline $\begin{array}{l}\text { NAD }{ }^{+} \text {-specific malic } \\
\text { enzim }\end{array}$ & $0.078 \pm 0.0005$ & $0.086 \pm 0.02$ & 1.10 \\
\hline Acetate kinase & $1.08 \pm 0.055$ & $0.35 \pm 0.078$ & 0.32 \\
\hline Lactate dehydrogenase & $0.39 \pm 0.009$ & $0.17 \pm 0.0045$ & 0.44 \\
\hline Citrate syntase & $0.10 \pm 0.005$ & $0.08 \pm 0.0045$ & 0.80 \\
\hline Malate dehydrogenase & $0.16 \pm 0.014$ & $0.15 \pm 0.012$ & 0.93 \\
\hline Isocitrate lyase & $0.016 \pm 0.082$ & $0.26 \pm 0.018$ & 16.25 \\
\hline Malate syntase & $0.12 \pm 0.002$ & $0.19 \pm 0.014$ & 1.58 \\
\hline $\begin{array}{l}\text { Isocitrate } \\
\text { dehydrogenase }\end{array}$ & $1.79 \pm 0.032$ & $0.31 \pm 0.056$ & 0.17 \\
\hline Transhydrogenase & ND & $0.036 \pm 0.001$ & - \\
\hline $\begin{array}{l}\text { Entner Doudoroff } \\
\text { pathway }\end{array}$ & $1.19 \pm 0.065$ & $2.46 \pm 0.101$ & 2.07 \\
\hline
\end{tabular}

Notes: The unit of enzyme activity is $\mathrm{mmol} \mathrm{min}^{-1} \mathrm{mg}$ protein ${ }^{-1}$. Overall Entner-Doudoroff (ED) pathway enzyme was represented as $\mathrm{mg}$ pyruvate $\mathrm{min}^{-1} \mathrm{mg}$ protein ${ }^{-1}$. The ratio of enzyme activity was calculated for pgi mutant over the corresponding value in the parent strain. Therefore, a value of 1.0 indicates no change in enzyme activities. Values presented are the average with deviation from triplicates measurements. ND Not detected. 
Table 3: Comparison of the enzyme activities in cell extracts of the parent and pgi mutant E.coli during chemostat culture at the dilution rate of $0.2 \mathrm{~h}^{-1}$.

\begin{tabular}{|c|c|c|c|}
\hline Enzyme & BW 25113 & pgi mutant & Ratio \\
\hline $\begin{array}{l}\text { Phosphoglucose } \\
\text { isomerase }\end{array}$ & $1.82 \pm 0.005$ & $0.22 \pm 0.006$ & 0.12 \\
\hline Glucokinase & $0.35 \pm 0.0132$ & $0.52 \pm 0.012$ & 1.49 \\
\hline Phosphofructose kinase & NM & NM & \\
\hline Fructose diphosphatase & $0.15 \pm 0.007$ & $0.13 \pm 0.007$ & 0.87 \\
\hline $\begin{array}{l}\text { Triosephosphate } \\
\text { isomerase }\end{array}$ & $0.06 \pm 0.006$ & $0.003 \pm 0.002$ & 0.05 \\
\hline $\begin{array}{l}\text { Glyceraldehyde 3- } \\
\text { phosphate } \\
\text { dehydrogenase }\end{array}$ & $0.05 \pm 0.004$ & $0.02 \pm 0.005$ & 0.40 \\
\hline Pyruvate kinase & $0.17 \pm 0.01$ & $0.15 \pm 0.02$ & 0.88 \\
\hline $\begin{array}{l}\text { Glucose-6-phosphate } \\
\text { dehydrogenase }\end{array}$ & $0.16 \pm 0.02$ & $0.22 \pm 0.003$ & 1.39 \\
\hline $\begin{array}{l}\text { 6-Phosphogluconate } \\
\text { dehydrogenase }\end{array}$ & $0.15 \pm 0.01$ & $0.32 \pm 0.006$ & 2.13 \\
\hline $\begin{array}{l}\text { Phosphoenol pyruvate } \\
\text { carboxylase }\end{array}$ & $0.09 \pm 0.065$ & $0.03 \pm 0.0005$ & 0.33 \\
\hline $\begin{array}{l}\text { Phosphoenol pyruvate } \\
\text { carboxykinase }\end{array}$ & $0.15 \pm 0.007$ & $0.20 \pm 0.02$ & 1.33 \\
\hline $\begin{array}{l}\text { NADP }{ }^{+} \text {-specific malic } \\
\text { enzim }\end{array}$ & $0.18 \pm 0.007$ & $0.18 \pm 0.007$ & 1.0 \\
\hline $\begin{array}{l}\text { NAD }{ }^{+} \text {-specific malic } \\
\text { enzim }\end{array}$ & $0.02 \pm 0.002$ & ND & 0 \\
\hline Acetate kinase & $0.44 \pm 0.011$ & $0.36 \pm 0.031$ & 0.82 \\
\hline Lactate dehydrogenase & $0.08 \pm 0.01$ & $0.03 \pm 0.001$ & 0.37 \\
\hline Citrate syntase & $0.02 \pm 0.003$ & $\begin{array}{l}0.009 \pm 0.000 \\
6\end{array}$ & 0.45 \\
\hline ase & $0.08 \pm 0$ & $0.14 \pm 0.002$ & 1.75 \\
\hline Malate syntase & $0.11 \pm 0.009$ & $0.14 \pm 0.002$ & 1.27 \\
\hline $\begin{array}{l}\text { Isocitrate } \\
\text { dehydrogenase }\end{array}$ & $1.76 \pm 0.16$ & $1.40 \pm 0.29$ & 0.79 \\
\hline Transhydrogenase & ND & $0.036 \pm 0.001$ & \\
\hline Entner Doudoroff & $0.95 \pm 0.016$ & $5.12 \pm 0.217$ & 5.38 \\
\hline
\end{tabular}
pathway

Notes: The unit of enzyme activity is $\mathrm{mmolmin}^{-1} \mathrm{mgprotein}^{-1}$. Overall Entner-Doudoroff (ED) pathway enzyme was represented as $\mathrm{mg}$ pyruvate $\mathrm{min}^{-1} \mathrm{mgprotein}^{-1}$. The ratio of enzyme activity was calculated for pgi mutant over the corresponding value in the parent strain. Therefore, a value of 1.0 indicates no change in enzyme activities. Values presented are the average with deviation from triplicates measurements. ND Not detected. NM Not measured

\section{Intracellular metabolite concentrations}

Some of the intracellular metabolite concentrations were also measured and compared between the parent and the mutant as shown in Figure 2 and 3. Significant changes in the intracellular metabolite concentrations were observed in response to pgi knock out. The glucose-6-phosphate (G6P) concentration was significantly higher (about 5 folds for both cultivations) in the mutant as compared with the wild type (Figure 2 and 3). A low level of oxaloacetate (OAA) concentration was observed in the mutant as compared to the parent strain. As a consequence, glyoxylate shunt was activated as shown by the increased activities of isocitrate lyase and malate synthase to replenish OAA pool. NADPH/NADP ${ }^{+}$ratio increased significantly (about 2 folds for batch culture and continuous culture) in the mutant strain (Figure 2 and 3 ). Overexpression of NADPH and limitation of NADPH reoxidation might results in the reduced growth of pgi mutant. The pool size of pyruvate (PYR) as a precursor for acetyl CoA which is located at the node of glycolysis and tricarboxylic acid (TCA) cycle exhibited lower concentration in pgi mutant as compared with the parent strain, indicating that the TCA cycle had a relatively higher activity than glycolysis in the mutant. The pgi mutant showed slightly lower $\mathrm{NADH} / \mathrm{NAD}^{+}$ratio as compared with the parent strain (Figure 2) indicating that the gene deletion was affected the intracellular redox balance.

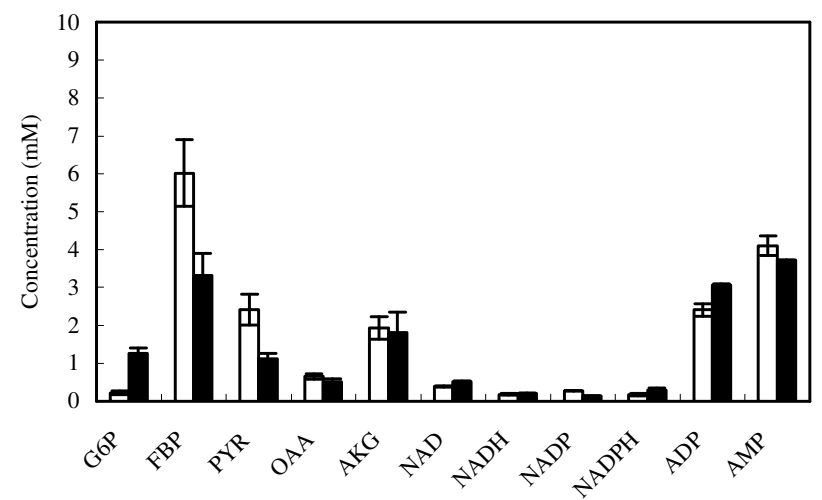

Figure 2: Intracellular metabolite concentrations at the exponential growth phase for both pgi mutant and parent E.coli (duplicate measurements). Standard deviations were calculated from triplicates measurements. ( $\square$ ) parent $(\square)$ pgi mutant.Glucose6-phosphate, G6P; Fructose-biphosphate, FBP; Oxaloacetate, OAA; $\propto$-ketoglutarate, AKG; Pyruvate, PYR; Nicotinamide adenine dinucleotide, NAD; Nicotinamide adenine dinucleotide reduced, NADH; Nicotinamide adenine dinucleotide phosphate, NADP; Nicotinamide adenine dinucleotide phosphate, reduced, NADPH; Adenine diphosphate, ADP; Adenosine Monophosphate, AMP.

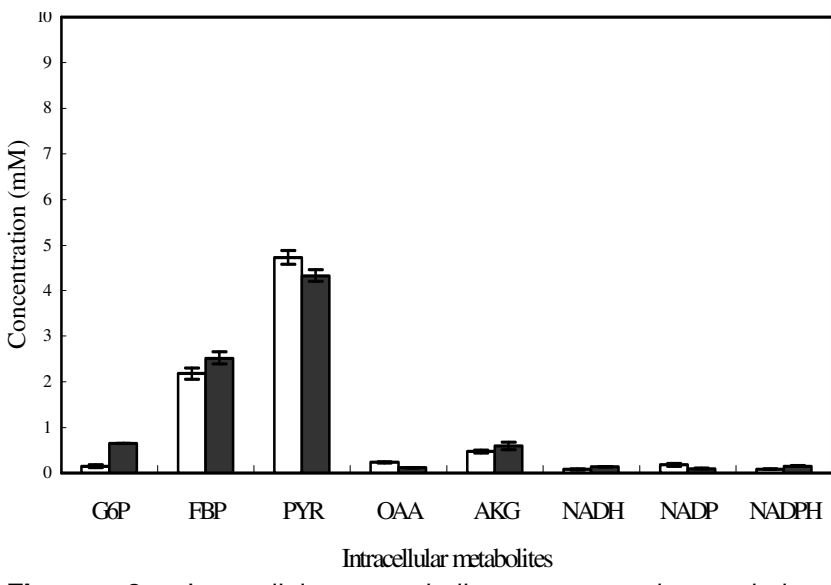

Figure 3: Intracellular metabolite concentrations during continuous culture for both pgi mutant and parent E.coli at the dilution rate of $0.2 \mathrm{~h}^{-1}$. Standard deviations were calculated from triplicates measurements. ( $\square$ ) parent (ם) pgi mutant. Abbreviations: see figure 2 . 


\section{DISCUSSION}

The present work indicates the importance of using integrated information from enzyme activities, intracellular metabolites and physiological parameters to investigate the metabolic response to genetic manipulation. The decreased of specific growth rate and specific consumption rate for pgi mutant as compared to the wild strain corresponded with the significantly change in the metabolic patterns in response to genetic manipulation. The most important function of the enzymatic study is to identify the network structure in terms of the activities of the pathways.

A continuous culture cultivation of pgi mutant and its parent strain in the same medium with glucose as a carbon source was performed. In continuous culture, under the steady state conditions, the microbial growth occurs at the constant growth rate and in a constant environment. Factors such as specific growth rate, nutrient and cell concentrations, concentration of metabolites, which inevitably change during the growth cycle in batch cycle, are all maintained constantly in continuous culture. The similar metabolic pattern of pgi mutant was observed for both batch and chemostat cultures as shown by the changes in the enzyme activities. Based on the enzymatic study, it is suggested that the pathways of pentose phosphate, EntnerDoudoroff pathway and glyoxylate shunt were all active in pgi mutant, while glycolysis and fermentative pathway was down regulated in the mutant as compared to the parent strain.

The knockout of pgi mutant gene in the present study causes the accumulation of glucose-6-phosphate. Morita et al. (2003) reported that glucose-6-phosphate (G6P) level in pgi mutant strain markedly increases as compared with that in the wild type strain. E.coli mutant lacking both pgi and zwf causes high concentration of G6P (Fraenkel, 1968). Saccharomyces cerevisiae pgi mutant can grow on media containing fructose and not more than $0.2 \%$ of glucose concentration since higher glucose concentration inhibits the cell growth due to the accumulation of G6P (Gamo et al., 1993). It has been reported that the accumulation of glucose-6-phosphate or fructose-6phosphate resulted in rapid degradation of pts $\mathrm{mRNA}$ in pgi and pfk mutant to avoid too much accumulation of hexose monophosphates in the mutant cell (Morita et al., 2003). The rapid degradation of pts $G$ mRNA in response to the accumulation of G6P implies an elaborate feedback regulatory mechanism. The down-regulation of $p t s G$ expression through mRNA degradation reduces the glucose uptake and reduces the accumulation of hexose monophosphates in the mutant cell.

The enzyme activities of glucose-6-phosphate dehydrogenase (G6PDH) and 6-phosphogluconate dehydrogenase (6PGDH) showed upregulation in pgi knockout mutant, while the glycolytic pathways were down regulated indicating that most the carbon flux are directed via the pentose phosphate pathway instead of glycolytic pathway. It was reported that phosphofructokinase and pyruvate kinase plays a major role in the regulation of glycolysis, and both exhibited down regulation in pgi mutant. Pyruvate kinase catalyzes the conversion of phosphoenolpyruvate (PEP) to pyruvate (PYR) coupled with the synthesis of one molecule of ATP. The enzyme activity of phosphoenol pyruvate carboxylase (Ppc) which catalyzes $\mathrm{CO}_{2}$-fixation from PEP yielding OAA was down regulated in the case of mutant in this study indicating that the knockout of the pgi gene resulted in less anaplerotic metabolism through this pathway. In most bacteria, the major physiological role of this enzyme is to replenish the TCA cycle by supplying OAA directly from PEP. The reduced activity of $\mathrm{Ppc}$ is evidenced by the reduced OAA originating from PEP and high fraction of OAA derived from the glyoxylate shunt in pgi mutant E.coli (Fisher and Sauer, 2003; Hua et al., 2003).

The activity of isocitrate dehydrogenase (ICDH) shows down regulation in pgi mutant. This phenomenon is similar when acetate was used as a carbon source and this reduction is a prerequisite for the activation of the glyoxylate shunt, since the affinity of ICDH for isocitrate is much higher than the lyase activity. In pgi mutant, activation of the glyoxylate shunt results in the reduced production of NADPH by ICDH (Hua et al., 2003). Isocitrate lyase and malate syntase exhibited upregulation in the mutant which represent the activation of glyoxylate shunt. In general, glyoxylate shunt is considered to be inactive in E.coli grown on glucose. The upregulation of glyoxylate was also shown in phosphoenolpyruvate carboxykinase deletion mutant (Yang et al., 2003). This phenomenon might be caused by the shortage of OAA and Ppc cannot fulfill the anaplerotic function. Both Ppc and glyoxylate shunt serve to replenish the carbon skeletons of OAA used for biosynthesis. The glyoxylate shunt is essential for growth on acetate or fatty acids since this pathway allows the net conversion of acetylCoA to metabolic intermediates. This pathway is regulated by the synthesis of three enzymes such as isocitrate lyase (ICl), malate synthase (MS), and isocitrate dehydrogenase kinase/phosphatase. Two of these, Icl and MS, act to convert some of the carbon flux from isocitrate to malate. Icl competes with ICDH for isocitrate. In E.coli, ICDH is regulated by phosphorylation to control the flow of isocitrate through the glyoxylate bypass. Phosphorylation of ICDH results in inactivation of the enzyme, since it blocks isocitrate binding by disrupting hydrogen bond and by introducing electrostatic repulsion between phosphate and isocitrate (Cronan and Laporte, 1996). The malate dehydrogenase in pgi mutant shows relatively low activity as compared with that of the parent. The activity of $\mathrm{MDH}$ is negatively regulated by ArcA regulatory protein, where it is upregulated in E.coli pgi mutant DF11 (Kabir, 2003). The downregulation of citrate synthase may be due to the same reason.

The E.coli pgi mutant showed higher NADPH/NADP ${ }^{+}$ as compared to its parent. NADPH and NADH are the major reducing powers in microorganisms. In general $\mathrm{NADPH}$ is associated with an anabolic reaction, while $\mathrm{NADH}$ is associated with catabolic and energy-yielding reactions. NADPH is mostly produced in the pentose phosphate pathway through the reactions of G6PDH and 
6PGDH (Lim et al., 2002) and those enzymes were found significantly upregulated in the mutant. Besides that, both ICDH and NADP ${ }^{+}$-specific Mez also contribute to NADPH production (Marx et al., 2003). In the present work, the specific activity of ICDH and $\mathrm{NADP}^{+}$-specific Mez were down regulated and not significantly changed for the latter. Therefore, it can be concluded that NADPH was overproduced through pentose phosphate pathway as shown by the upregulation of pentose phosphate pathway in the E.coli pgi mutant. The activation of EntnerDoudoroff pathway reduces the overproduction of NADPH in the pentose phosphate pathway (Fishcer and Sauer, 2003). The transhydrogenases reaction may be utilized to balance NADPH and NADH. Escherichia coli contains two transhydrogenase isoforms. These enzyme activities show upregulation in the mutant, although the assay could not distinguish between the membrane bound PntAB and the soluble transhydrogenase UdhA. The rapid consumption of $\mathrm{NADP}^{+}$and insufficient rate of regeneration of $\mathrm{NADP}^{+}$from $\mathrm{NADPH}$ prevent the direct oxidation, and thus a transhydrogenase system is activated for pgi mutant to grow on glucose (Boles et al., 1993). The PntAB is unlikely to catalyze sufficient reoxidation of NADPH since pgi pntAB double mutant still grows slowly as well as the pgi mutant, which means that the reoxidation through $\mathrm{Pnt} A \mathrm{~B}$ does not play an important role. On the other hand, the overexpression of the soluble transhydrogenase UdhA in pgi mutant results in the increase of its specific growth rate by about $25 \%$ (Canonaco et al., 2001). This report shows the evidence for a physiological role of the soluble transhydrogenase in the reoxidation of NADPH.

One of the goals of a gene knockout study is the engineering of metabolic pathways for enhanced production of industrial chemicals. Genetically altering metabolic pathway, however, often causes undesirable changes such as reduced growth, decreased glycolytic flux, and the creation of futile cycles, which may limit its utility (Zhao et al., 2003). The pgi disruption may be used for the metabolic engineering of the biotechnological synthesis of chemicals specific to the pentose phosphate pathway intermediates such as tryptophan, histidine etc. (Mascarenhas, 1991). Another possibility is to utilize the phenomenon of NADPH overproduction by coupling the NADPH consuming pathway reactions. One such example is to couple the reaction through acetoacetyl-coA reductase reaction in polyhydroxybutyrate (PHB) production. Another example is the amplification of the glutamate dehydrogenase in pgi mutant which leads to a very efficient production of glutamate (Boles et al., 1993). Moreover, in the case of pgi mutant E.coli which exhibits slow growth on glucose due to imbalance of the reducing power, the cell growth can be improved by overexpression of the soluble transhydrogenase UdhA to reoxidize NADPH overproduction.

\section{REFERENCES}

Bergmeyer, H.U. (1984). Methods of enzymatic analysis, vol $6,3^{\text {rd }}$ ed. VCH, Weinheim, Germany.
Bergmeyer, H.U.(1985). Methods of enzymatic analysis, vol 7, $3^{\text {rd }}$ ed. VCH, Weinheim, Germany.

Bradford, M.M. (1976). A rapid and sensitive method for the quantitation of microgram quantities of protein utilizing the principle of protein-dye binding. Analytical Biochemistry 72: 248-254.

Boles, E., Lehnert, W. and Zimmermann, F.K. (1993). The role of the $N A D^{+}$-dependent glutamate dehydrogenase in restoring growth on glucose of Saccharomyces cerevisiae phosphoglucose isomerase mutant. European Journal Biochemistry 217: 469-477.

Canonaco, F., Hess, T.A., Heri, S., Wang, T., Syperperski, T. and Uwe Sauer. (2001). Metabolic flux response to phosphoglucose isomerase knockout in Escherichia coli and impact of overexpression of the soluble transhydrogenase UdhA. FEMS Microbiology Letters 204: 247-252.

Cronan, J.E. and Laporte, J.R. (1996). Tricarboxylic acid cycle and Glyoxylate Bypass. In: Neidhardt FC, Curtiss R, Ingraham JL, Lin ECC, Low KB, Magasanik B, Reznikoff WS, Riley M, Schaechter M, Umbarger HE, eds. Escherichia coli and Salmonella: Cellular and Molecular Biology. Washington DC: ASM Press, pp 206-216.

Datsenko, K.A. and Wanner, B.L. (2000). One-step inactivation of chromosomal genes in Escherichia coli K-12 using PCR products. Proceeding National Academic Science USA 97:6640-6645.

Dominguez, H., Rollin, C., Guyonvarch, A., Guerquin, K., Cocaign-Bousquet, M. and Lindley, N.D. (1998). Carbon-flux distribution in the central metabolic pathways of Corybacterium glutamicum during growth on fructose. European Journal Biochemistry. 254: 96102.

Fischer, E. and Sauer, U. (2003). Metabolic flux profiling of Escherichia coli mutants in central carbon metabolism using GC-MS. European Journal Biochemistry 270: 880-891.

Fraenkel, D.G. (1968). The accumulation of glucose-6phosphate from glucose and its effect in an Escherichia coli mutant lacking phosphoglucose isomerase and glucose-6-phosphate dehydrogenase. The Journal of Biological Chemistry 243(24): 65416457.

Gamo, F.J., Portillo, F. and Gancedo, C. (1993). Characterization of mutations that overcome the toxic effect of glucose on phosphoglucose isomerase less strain of Saccharomyces cerevisiae. FEMS Microbiology Letters 106: 233-238.

Hua, Q., Yang, C., Baba, T., Mori, H. and Shimizu, K. (2003). Responses of the central metabolism in Escherichia coli to phosphoglucose isomerase and glucose-6-phosphate dehydrogenase knockouts. Jornal of Bacteriology 185: 7053-7067.

Kabir, M. (2003). Metabolic pathway analyses of recombinant Escherichia coli based on gene and protein expressions. Ph.D thesis. Kyushu Institute of Technology. pp 79-80. 
Kabir, M.M., Ho, P.Y. and Shimizu, K. (2005). Effect of IdhA deletion on the metabolism of Escherichia coli based on gene expression, enzyme activities, intracellular metabolite concentrations and metabolic flux distribution. Biochemical Engineering Journal. 26:1-11.

Kyra, J.C., Justin, A.M., Janet, M.S. and Kenneth, B.S. (2000). Metabolic reorganization and signal transduction during estivation in the spade foot toad. Experimental Biology Online (EBO) 5(1): 1430-3418.

Lim, S.J., Jung, Y.M., Shin, H.D. and Lee, Y.H. (2002). Amplication of the NADPH-related genes $z w f$ and gnd for the oddball biosynthesis of PHB in an E.coli transformant harboring a cloned phbCAB operon. Journal of Bioscience and Bioengineering 93 (6): 543-549.

Marx, A., Hans, S., Mockel, B. and de Graaf, A.A. (2003). Metabolic phenotype of phosphoglucose isomerase mutant of Corynebacterium glutamicum. Journal of Biotechnology 104: 185-197.

Mascarenhas, D., Ashworth, D.J. and Chen, C.S. (1991). Deletion of pgi alters tryptophan biosynthesis in a genetically engineered strain of Escherichia coli. Applied and Environmental Microbiology 57(10): 2995-2999.

Morita, T., El-Kazzaz, W., Tanaka, Y., Inada, T. and Aiba, H. (2003). Accumulation of glucose-6phosphate or fructose-6-phosphate is responsible for destabilization of glucose transporter mRNA in Escherichia coli. The Journal of Biological Chemistry 278(18): 15608-15614.

Petersen, S., Mack, C., de Graaf, A.A., Riedel, C., Eikmanns, B. and Sahm, H. (2001). Metabolic consequences of altered phosphoenolpyruvate carboxykinase activity in Corynebacterium glutamicum reveal anaplerotic regulation mechanisms in vivo. Metabolic Engineering 3: 344-361.
Schreyer, R. and Bock, A. (1980). Phosphoglucose isomerase from Escherichia coli K10: Purification, properties and formation under aerobic and anaerobic conditions. Archieves Microbiology. 127: 289-298.

Sauer, U., Canonaco, F., Heri, S., Perrenound, A. and Fischer, E. (2004). The soluble and membranebound transhydrogenase UdhA and PntAB have divergent functions in NADPH metabolism of Escherichia coli. Journal of Biological Chemistry. 279: 6613-6619.

Sprenger, G.A. (1995). Genetics a pentose-phosphate pathway enzymes of Escherichia coli K-12. Archieves Microbiology. 164: 324-330.

Wang, Z.X., Bramer, C. and Steinbuchel, A. (2003). Two phenotypically isocitrate dehydrogenases in Ralstonia eutropha. FEMS Microbiology 227: 9-16.

Yang, C., Hua, Q., Baba, T., Mori, H. and Shimizu, K. (2003). Analysis of Escherichia coli anaplerotic metabolism and its regulation mechanisms from the metabolic response to altered dilution rates and phosphoenolpyruvate carboxykinase knockout. Biotechnology and Bioengineering 84 (2): 129-144.

Zhao, J. and Shimizu, K. (2003). Metabolic flux analysis of Escherichia coli $\mathrm{K} 12$ grown on ${ }^{13} \mathrm{C}$-labeled acetate and glucose using GC-MS and powerful flux calculation method. Journal of Biotechnology 101: 101-117. 